ARTICLE

\title{
Photo splitting of bio-polyols and sugars to methanol and syngas
}

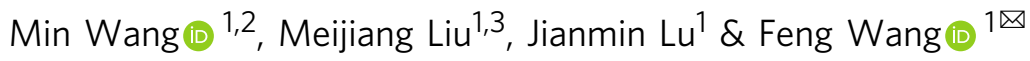

Methanol is a clean liquid energy carrier of sunshine and a key platform chemical for the synthesis of olefins and aromatics. Herein, we report the conversion of biomass-derived polyols and sugars into methanol and syngas $\left(\mathrm{CO}+\mathrm{H}_{2}\right)$ via UV light irradiation under room temperature, and the bio-syngas can be further used for the synthesis of methanol. The cellulose and even raw wood sawdust could be converted into methanol or syngas after hydrogenolysis or hydrolysis pretreatment. We find $\mathrm{Cu}$ dispersed on titanium oxide nanorod (TNR) rich in defects is effective for the selective $\mathrm{C}-\mathrm{C}$ bond cleavage to methanol. Methanol is obtained from glycerol with a co-production of $\mathrm{H}_{2}$. A syngas with $\mathrm{CO}$ selectivity up to $90 \%$ in the gas phase is obtained via controlling the energy band structure of $\mathrm{Cu} / \mathrm{TNR}$.

\footnotetext{
${ }^{1}$ State Key Laboratory of Catalysis, Dalian National Laboratory for Clean Energy, Dalian Institute of Chemical Physics, Chinese Academy of Sciences, 116023 Dalian, Liaoning, China. ${ }^{2}$ Zhang Dayu School of Chemistry, Dalian University of Technology, 116024 Dalian, Liaoning, China. ${ }^{3}$ University of Chinese Academy of Sciences, 100049 Beijing, P. R. China. ${ }^{凶}$ email: wangfeng@dicp.ac.cn
} 
E xploring renewable and clean energy as alternatives for fossil fuel has aroused a great research interest in sustainable development. Methanol is recognized to be the most promising clean and large scale deployment liquid fuel in the future because it has been identified as a viable alternative liquid fuel to gasoline and diesel, which can use existing global supply chains for storage, shipping, and distribution ${ }^{1}$. Moreover, methanol is a fundamental chemical material and has been industrially used for the production of ethylene and propylene and also promising for the synthesis of aromatics and gasoline ${ }^{2}$. Currently, methanol is industrially produced from natural gas and $\mathrm{coal}^{3}$. The production of methanol from renewable and abundant carbon resource instead of from fossils is a promising route for both fuel and chemicals purpose ${ }^{4,5}$.

Biomass, with global production of 170 billion metric tons per year, store the solar energy in the chemical bonds via plants biological photosynthesis, but cannot be directly used as a liquid fuel $^{4,6}$. The conversion of biomass into fuels have been widely studied $^{4,7-10}$. The conversion of biomass into bio-methanol, called as liquid sunshine ${ }^{1}$, efficiently connects the biorefinery processes and the existing petrochemical-fuel chains. The production of bio-methanol was fundamentally investigated via bioderived syngas ${ }^{11,12}$. Syngas itself is a very important platform chemical and can be converted into olefins and aromatics ${ }^{13,14}$, but it is challenging to selectively break up all the robust $\mathrm{C}-\mathrm{C}$ bond over $\mathrm{C}-\mathrm{O}$ bond to generate $\mathrm{CO}$ from biomass. Traditionally, biomass gasification via pyrolysis, partial oxidation or reforming at high temperature $\left(700-1000{ }^{\circ} \mathrm{C}\right)$ usually generates a mixture of $\mathrm{CO}, \mathrm{CO}_{2}$, hydrocarbons, and deficient $\mathrm{H}_{2}$ along with the formation of coke, char and $\operatorname{tar}^{4,15}$. The generation of a large amount of $\mathrm{CO}_{2}$ and hydrocarbons not only lowers the carbon atom economy but also affects the end usage of the bio-syngas. A catalytic thermal reforming has been reported for selective conversion of biomass into syngas, but still needs to be operated at a temperature higher than $300^{\circ} \mathrm{C}$ and limited to the $\mathrm{C} 2-\mathrm{C} 3$ based polyols, such as glycerol and ethylene glycol ${ }^{16,17}$. Cellulose was recently reported being converted into syngas under low temperature $\left(70^{\circ} \mathrm{C}\right)$ via stoichiometric oxidation with polyoxometalate followed by electrolysis, but using concentrated $\mathrm{H}_{2} \mathrm{SO}_{4}$ solvent ${ }^{18}$.

Compared to indirect production of methanol from bio-syngas, direct production of methanol from biomass is more difficult and has been rarely explored ${ }^{19}$. It is challenging to only break up the robust $\mathrm{C}-\mathrm{C}$ bond but not affect the $\mathrm{C}-\mathrm{H} / \mathrm{C}-\mathrm{O}$ bonds. Only C2-C3 based polyols, such as glycerol and ethylene glycol, were studied but suffered from low efficiency. Tsang et al. reported the hydrogenolysis of ethylene glycol (EG) to methanol over $\mathrm{Pd} /$ $\mathrm{Fe}_{2} \mathrm{O}_{3}$ with about $6 \%$ yield ${ }^{20}$. Hutchings et al. realized the $\mathrm{H}_{2}$-free production of methanol from glycerol reforming over simple basic oxide with $40-60 \%$ yield at above $300{ }^{\circ} \mathrm{C}^{21}$.

In this work, we propose a photo splitting method for the conversion of biomass into syngas and methanol (Fig. 1). We find $\mathrm{Cu}$ dispersed on titanium oxide nanorod $(\mathrm{Cu} / \mathrm{TNR})$ is effective for the conversion of polyols and sugars into syngas and

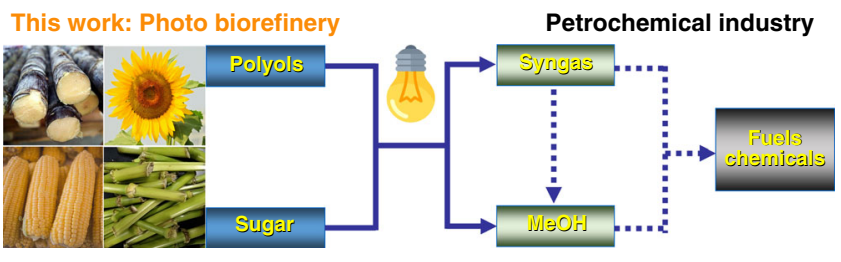

Fig. $1 \mathrm{~A}$ concept of bridging biorefinery and petrochemical industry. Methanol and syngas act as the platform chemical connecting the biorefinery and petrochemical industry. methanol under UV light irradiation at room temperature. The gas product can be facially tuned from $\mathrm{CO}_{2}$ to $\mathrm{CO}$ via controlling the energy band structure of $\mathrm{Cu} / \mathrm{TNR}$. The cellulose and even raw wood sawdust could be converted into methanol or syngas after hydrogenolysis or hydrolysis pretreatment.

\section{Results}

Photoreforming of glycerol. Catalyst screening. Glycerol is a byproduct in the production of biodiesel at roughly one-tenth the mass of the biodiesel. Well-utilization of the glycerol has become a bottleneck for the biodiesel technology and is providing a brake on further development ${ }^{22}$. We firstly investigated the photo-reforming of glycerol. Direct cleavage of the $\mathrm{C}-\mathrm{C}$ bond via conventional thermal-catalysis requires to be performed at a high temperature accompanied by the risk of over decomposition and carbonization. Light-driven photocatalysis is a promising strategy to realize the $\mathrm{C}-\mathrm{C}$ bond cleavage under mild conditions but the over oxidation generally occurs. Besides some works on the generation of useful chemicals from photoreforming of biomass resources ${ }^{23,24}$, most of the carbon are eventually converted into $\mathrm{CO}_{2}$ (A summary of photoreforming of glycerol was shown Supplementary Table 1). It is a challenge to selectively cleave $\mathrm{C}-\mathrm{C}$ bond and avoid the overoxidation reactions. We firstly screened a series of semiconductor photocatalysts in the photo-reforming of glycerol in MeCN-water (8:2) solution under $365 \mathrm{~nm}$ LED irradiation (Fig. 2a). Most of the widely used catalysts were inactive for this reaction. A trace amount of methanol was found in the case of P25. The loading of $\mathrm{Fe}, \mathrm{Co}$ and $\mathrm{Ni}$ on P25 did not improve the catalytic performance, and methanol was not detected. When copper was loaded in the $\mathrm{TiO}_{2}-\mathrm{R}, \mathrm{TiO}_{2}-\mathrm{A}, \mathrm{P} 25, \mathrm{CO}_{2}$ was generated as the major product. $\mathrm{Pt} / \mathrm{P} 25$ is very active but generates a large amount of $\mathrm{CO}_{2}$ and $\mathrm{H}_{2}$. In comparison, immobilization of copper on titanium oxide nanorod $(1 \mathrm{Cu} / \mathrm{TNR})$ prefers to produce methanol, and $30 \%$ yield of methanol were produced along with a generation of $15 \mathrm{mmol}$ $\mathrm{g}_{\text {cat. }}{ }^{-1}$ of $\mathrm{H}_{2}$. We found $\mathrm{MeCN}$ is the best co-solvent in combination with $\mathrm{H}_{2} \mathrm{O}$ (Supplementary Fig. 1). The volume ratio of MeCN to $\mathrm{H}_{2} \mathrm{O}$ affects catalytic performance (Supplementary Fig. 2). The ratio of $\mathrm{MeCN}$ to $\mathrm{H}_{2} \mathrm{O}$ with $8: 2$ is a suitable solvent system to achieve a high yield of methanol. The copper loading of $\mathrm{Cu}$ /TNR showed a significant effect on the production of methanol from glycerol (Fig. 2a and Supplementary Fig. 3). The yield of methanol firstly increases with the copper loading and reaches a maximum yield at 1-2 wt $\%$ copper loading, and then declines with further increase in the content of copper beyond $2 \mathrm{wt} \%$. As the reaction proceeded, the yield of methanol gradually increased and then decreased (Fig. 2b), indicating the decomposition of glycerol and methanol are two competitive routes. After optimization, about $40 \%$ yield of methanol is reached over $2 \mathrm{Cu} / \mathrm{TNR}$, along with $31 \%$ yield of $\mathrm{CO}_{2}, 3.6 \%$ yield of $\mathrm{CO}$ and $22 \mathrm{mmol} \mathrm{g}_{\text {cat. }}-1$ of $\mathrm{H}_{2}$. The apparent quantum yield is $3.4 \%$. We tried to use sunlight for this reaction, but much lower activity was obtained due to the small content of UV light in the solar light. Under solar irradiation for $16 \mathrm{~h}$, only $4 \%$ yield of methanol was produced along with a generation of $0.8 \mathrm{mmolg}_{\mathrm{cat}}{ }^{-1} \mathrm{~h}^{-1}$ of $\mathrm{H}_{2}$. In order to exclude the methanol comes from $\mathrm{MeCN}$ solvent. We performed the photoreaction in the absence of glycerol. Methanol was not detected and only a very minor amount of $\mathrm{CO}_{2}$ detected (Supplementary Fig. 4). These results demonstrate that the acetonitrile is relatively stable under the reaction conditions and methanol is not originated from $\mathrm{MeCN}$ degradation.

Photoreforming of polyols and sugars. Then, we investigated the photo-reforming of other biomass resources over 2Cu/TNR (Fig. 2d). C2-C6 polyol, such as ethylene glycol (EG), 1,2-propanediol, erythritol, xylitol, and sorbitol were all facilely converted to 


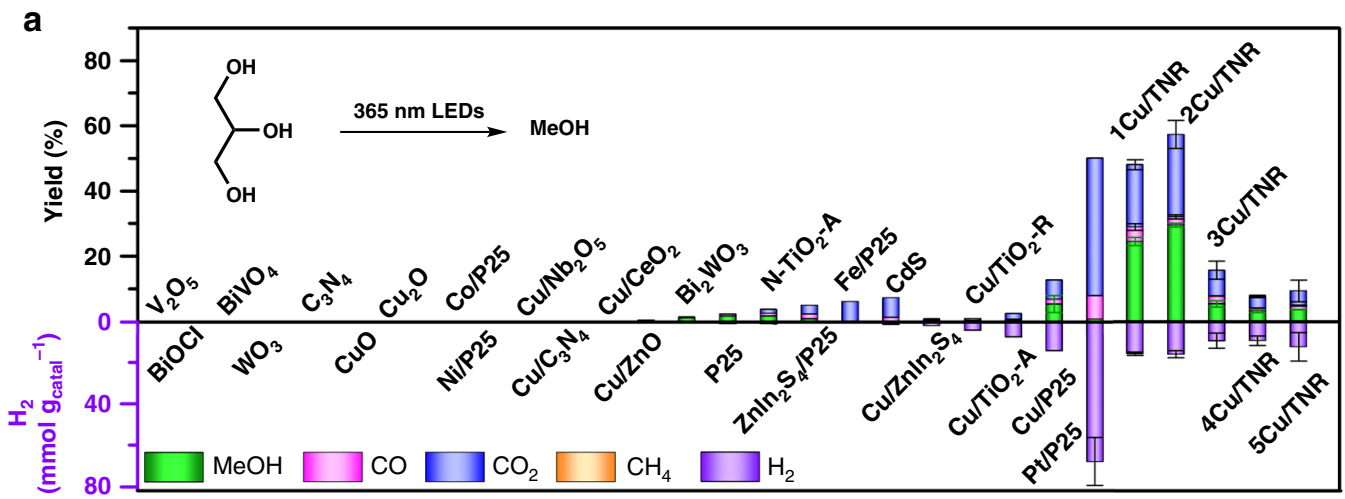

b

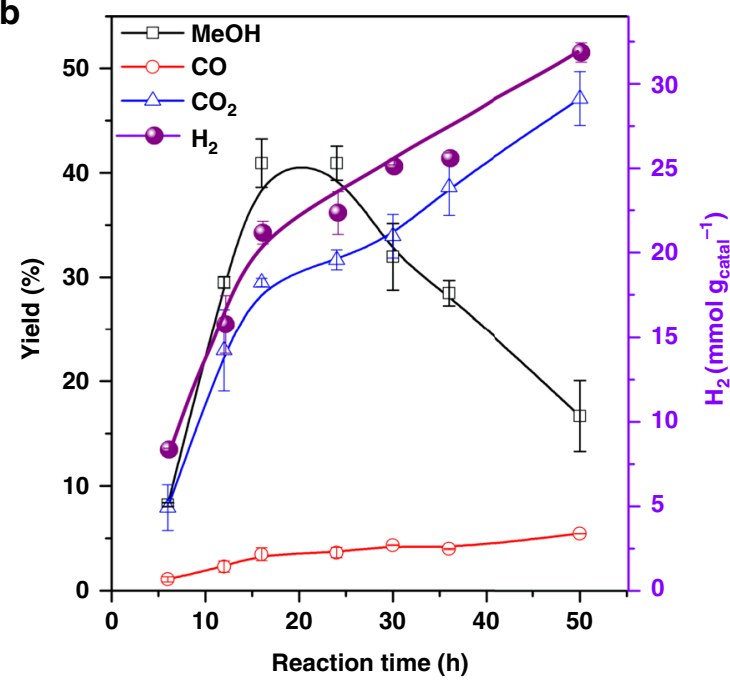

C

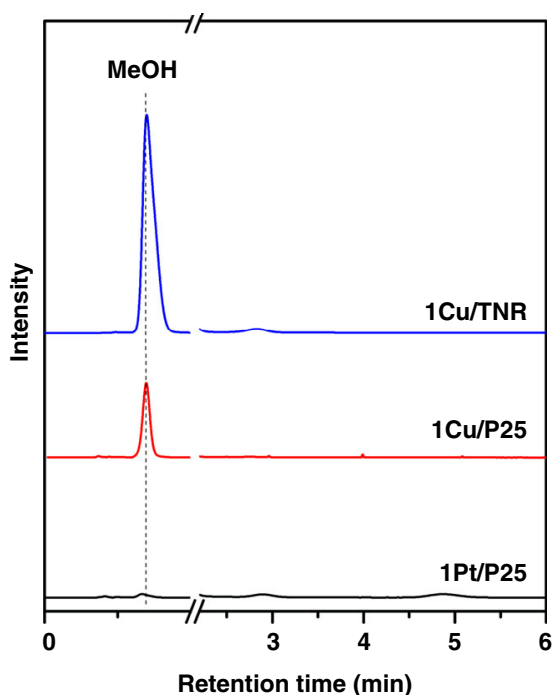

\section{d}

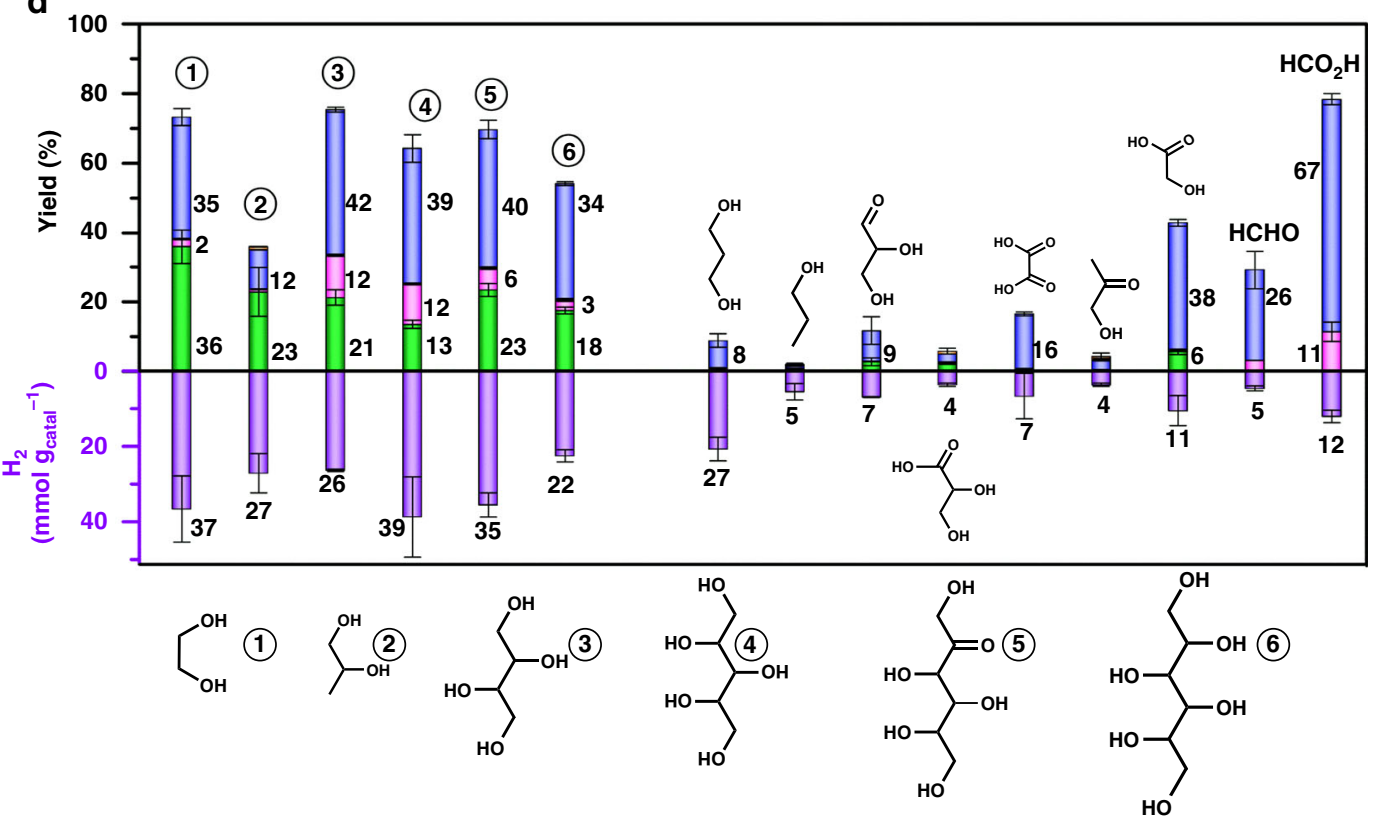

Fig. 2 Conversion of biomass resources to methanol. a Catalyst screening. Reaction conditions: $10 \mathrm{mg}$ of glycerol, $10 \mathrm{mg}$ of catalyst, $0.8 \mathrm{~mL}$ of $\mathrm{MeCN}$, $0.2 \mathrm{~mL}$ of water, $365 \mathrm{~nm} \mathrm{LED} \mathrm{(18} \mathrm{W,} 55 \mathrm{~mW} \mathrm{~cm}^{-2}$ ) irradiation for $12 \mathrm{~h} . \mathbf{b}$ The effect of reaction time. c GC curves of liquid phase products. d Photoreforming of different oxygenates. Detailed reaction conditions and product analysis are presented in Supplementary Tables 2, 3. Error bar represents the standard deviation. 
methanol in $10-40 \%$ yields along with a generation of 20-40 mmol gat. ${ }^{-1}$ of $\mathrm{H}_{2}$. The polyols with longer carbon chains are more reluctant to react and need a longer reaction time (Supplementary Table 4). Fructose was converted to methanol in $23 \%$ yield. Methanol was formed from 1,2-propanediol with $22 \%$ yield, but not from 1,3-propanediol and 1-propanol or 2-propanol, indicating that molecules require the vicinal diol structure for this reaction. Although the structures of the substrates are different, the liquid products are similar which is probably due to that all the substrate are possessed of vicinal diol structure and probably undergo similar $\mathrm{C}-\mathrm{C}$ bond cleavage route.

Controlling the ratio of $\mathrm{CO}$ to $\mathrm{CO}_{2}$. Although methanol was obtained from various biomass resources, a large amount of $\mathrm{CO}_{2}$ was also produced along with $\mathrm{H}_{2}$ in the gas phase. If $\mathrm{CO}$ is generated instead of $\mathrm{CO}_{2}$, a syngas will be produced. Syngas can be further converted into methanol ${ }^{11,12,25-28}$. We further attempted to improve the selectivity of CO. In order to prevent the formation of $\mathrm{CO}_{2}$ and increase the selectivity of $\mathrm{CO}$, we optimized the reaction conditions and the structure of $\mathrm{Cu} / \mathrm{TNR}$. The water concentration and copper loading were two key factors that influence the $\mathrm{CO} / \mathrm{CO}_{2}$ ratio (Fig. 3a). $\mathrm{CO} / \mathrm{CO}_{2}$ ratio increases with a decrease in water concentration. The $\mathrm{CO}_{2}$ comes from the decarboxylation of carboxylic acids which are generated via reaction with $\mathrm{HO}$. radicals ${ }^{7}$. We have detected the hydroxyl radical using electron paramagnetic resonance (EPR), and 5,5-dimethyl-1-pyrroline $\mathrm{N}$-oxide (DMPO) was used to capture the hydroxyl radicals (Supplementary Fig. 5). In water solvent, the signals of hydroxyl radicals were detected. When decreasing the water content to $5 \%$, no obvious signals of hydroxyl radicals were observed. It can be deduced that decreasing the concentration of water reduces the hydroxyl radicals and thus slows down the degradation of organic species to $\mathrm{CO}_{2}$.

The copper loading amount shows a more remarkable effect on the $\mathrm{CO} / \mathrm{CO}_{2}$ ratio. The $\mathrm{CO} / \mathrm{CO}_{2}$ ratio slowly increases from 0.5 to 1 when the copper loading is reduced from $5 \mathrm{wt} \%$ to $0.5 \mathrm{wt} \%$. Further decreasing the copper loading below $0.5 \mathrm{wt} \%$ significantly favors the formation of $\mathrm{CO}$. The $\mathrm{CO} / \mathrm{CO}_{2}$ ratio sharply increases from 1 to 9.6 when the copper loading is decreased from $0.5 \mathrm{wt} \%$ to $0.01 \mathrm{wt} \%$. With $0.1 \mathrm{Cu} / \mathrm{TNR}$ as a catalyst, $\mathrm{CO}$ was favorably produced even in pure water with a $\mathrm{CO} / \mathrm{CO}_{2}$ ratio of 2 . At the same loading amount of metal, 0.1Pt/TNR, 0.1Pt/TiO $2-\mathrm{A}, 0.1 \mathrm{Cu} / \mathrm{TiO}_{2}-\mathrm{A}$, and $0.1 \mathrm{Cu} / \mathrm{P} 25$ all gave a low $\mathrm{CO} / \mathrm{CO}_{2}$ ratio $(0.5-1)$. As the reaction proceeded, the yields of $\mathrm{CO}$ and $\mathrm{CO}_{2}$ gradually increased, while the yield of methanol first increased and then decreased (Supplementary Fig. 6). This indicates that methanol can be further decomposed to $\mathrm{CO}$ and $\mathrm{H}_{2}$. Under optimized conditions, 27\% yield of methanol and 45\% yield of CO were obtained along with $\mathrm{H}_{2} / \mathrm{CO}$ ratio of 0.8 and $96 \%$ conversion of glycerol. We further investigated other biomass
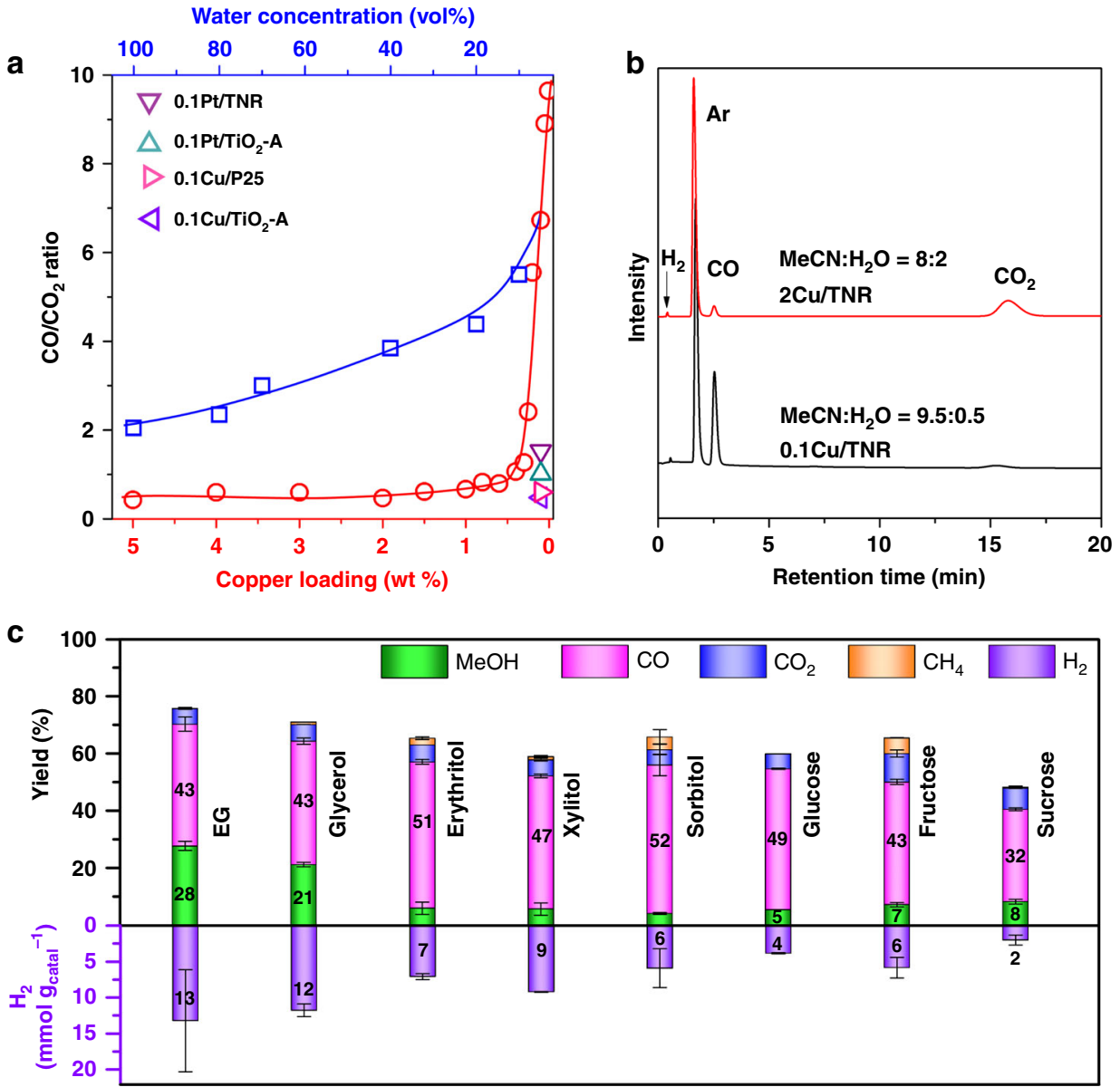

Fig. 3 Conversion of biomass resources to syngas. a The effect of water content and copper loading on the ratio of $\mathrm{CO} / \mathrm{CO}_{2}$. Reaction conditions: $10 \mathrm{mg}$ of glycerol, $10 \mathrm{mg}$ of catalyst, $365 \mathrm{~nm} \mathrm{LED}\left(18 \mathrm{~W}, 55 \mathrm{~mW} \mathrm{~cm}^{-2}\right)$ irradiation for $12 \mathrm{~h}$. For the investigation of water concentration effect, $0.1 \mathrm{Cu} / \mathrm{TNR}$ was used as a catalyst. For the investigation of copper loading effect, $0.95 \mathrm{~mL}$ of $\mathrm{MeCN}$ and $0.05 \mathrm{~mL}$ of water was used as solvent. $\mathbf{b} \mathrm{GC}$ curves of the gas products. c Photo-reforming of different polyols. Error bar represents the standard deviation. Detailed reaction conditions and product analysis are presented in Supplementary Table 4. 
a

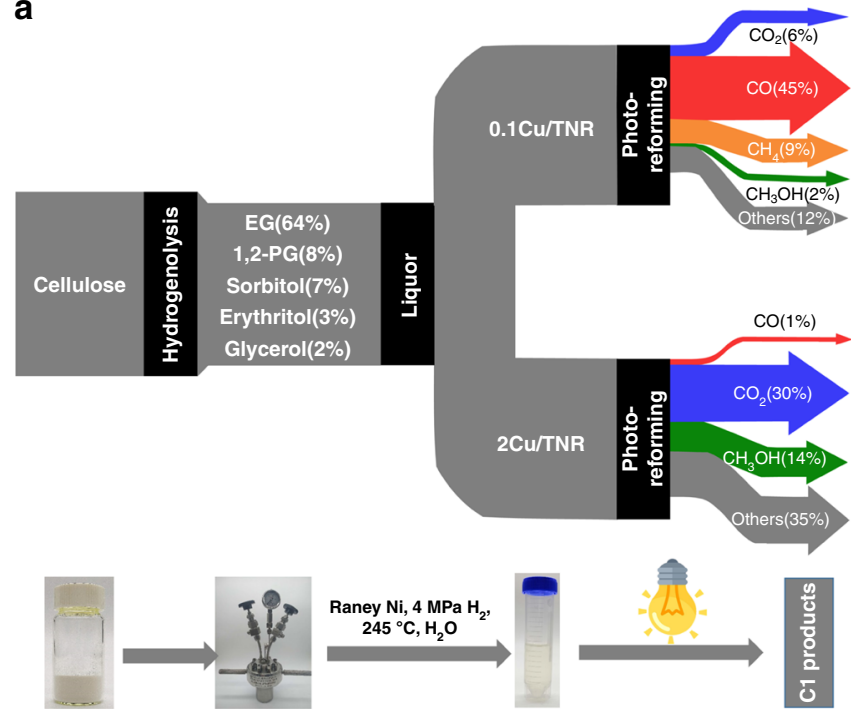

b

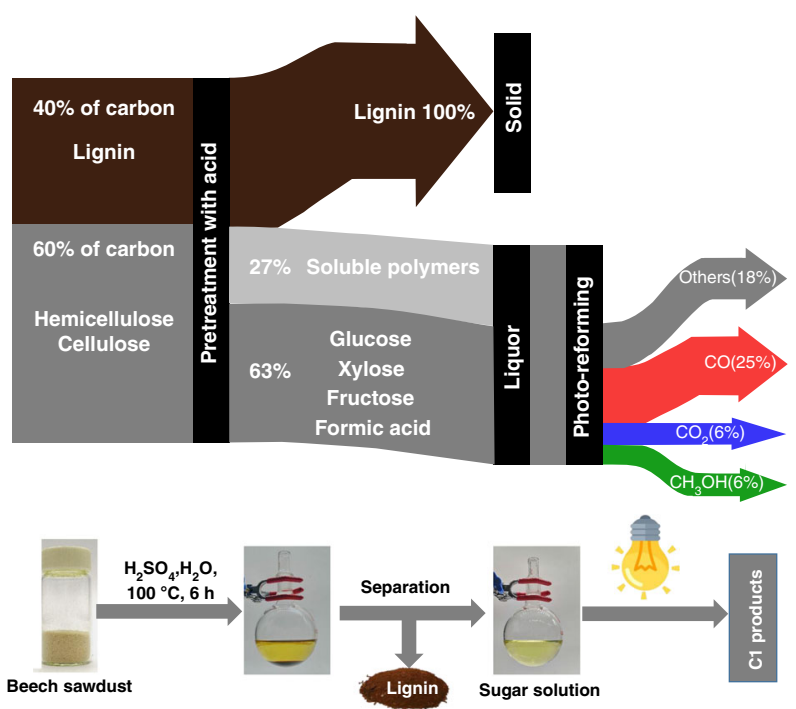

Fig. 4 Two-step strategy for the conversion of cellulose and sawdust into methanol and syngas. a Cellulose $\mathbf{b}$ beech sawdust. Detailed reaction conditions and product analysis are presented in Supplementary Tables 5, 6.

resources, such as sugars and sugar alcohols. Ethylene glycol (EG) was converted into methanol (28\%), $\mathrm{CO}(43 \%)$, and $\mathrm{CO}_{2}(5 \%)$. Compared with glycerol and EG, sugars and sugar alcohols possess longer carbon chains and require a longer reaction time to achieve a high CO yield. Sugar alcohols, including erythritol, xylitol, and sorbitol, are converted into $6-10 \%$ yield of $\mathrm{MeOH}, 46-52 \%$ yield of $\mathrm{CO}, 5-6 \%$ yield of $\mathrm{CO}_{2}$ and $1-5 \% \mathrm{CH}_{4}$ along with 5-10 mmol $\mathrm{g}_{\text {cat. }}{ }^{-1}$ of $\mathrm{H}_{2}$. Monosaccharides, such as fructose and glucose, are facially converted into $\mathrm{CO}$ and methanol. With $0.1 \mathrm{Cu} / \mathrm{TNR}$ as a catalyst, $5 \%$ yield of $\mathrm{MeOH}$ and $49 \%$ yield of $\mathrm{CO}$ was obtained from glucose, and $7 \%$ yield of $\mathrm{MeOH}$ and $43 \%$ yield of $\mathrm{CO}$ was produced if fructose was used as the feed. Sucrose, which consists of one glucose and fructose, is relatively inert and was converted into $8 \%$ yield of $\mathrm{MeOH}$ and $32 \%$ yield of $\mathrm{CO}$.

Conversion of cellulose and beech sawdust. Cellulose is the most abundant biomass resources and rich in diol structure, which is a promising candidate for the synthesis of methanol and syngas. Nevertheless, the insolubility and polymeric properties of the cellulose make it inert to be directly converted using the present method. We then tried to convert cellulose via a two-step strategy (Fig. 4a). In the first step, cellulose was hydrogenolyzed to a mixture of soluble polyols. Then, the polyols mixture was subjected to a photo-reforming reaction. Using $0.1 \mathrm{Cu} / \mathrm{TNR}$ as a catalyst, $45 \%$ yield of $\mathrm{CO}, 6 \%$ yield of $\mathrm{CO}_{2}$ and $9 \%$ yield of $\mathrm{CH}_{4}$ along with $9.5 \mathrm{mmolg}_{\text {cat. }}{ }^{-1}$ of $\mathrm{H}_{2}$ in the gas phase were obtained. With $2 \mathrm{Cu} /$ TNR as a catalyst, $14 \%$ yield of methanol was produced together with $30 \%$ yield of $\mathrm{CO}_{2}$ and $1 \%$ yield of $\mathrm{CO}$ in the gas phase.

Finally, we tried to use the raw sawdust as the substrate via a two-step strategy (Fig. 4) Beech sawdust was firstly treated in an acidic solution. The solid lignin which contains $40 \%$ of carbon of beech sawdust was removed, generating a sugar solution which contains $31 \%$ of glucose, $20 \%$ of xylose, $8 \%$ of fructose and $4 \%$ of formic acid based on the total carbon of (hemi)cellulose. After photoreaction over $0.1 \mathrm{Cu} / \mathrm{TNR}, 6 \%$ yield of methanol, $6 \%$ yield of $\mathrm{CO}_{2}$ and $25 \%$ yield of $\mathrm{CO}$ were produced accompanied by the generation of $\mathrm{H}_{2}$. Overall, $1 \mathrm{~g}$ of beech sawdust will produce $50 \mathrm{mg}$ of methanol in the liquid phase and $212 \mathrm{~mL}$ of gas consisting of $140 \mathrm{~mL}$ of $\mathrm{CO}, 36 \mathrm{~mL}$ of $\mathrm{CO}_{2}$, and $36 \mathrm{~mL}$ of $\mathrm{H}_{2}$, together with $240 \mathrm{mg}$ of lignin solid.

The reaction mechanism study. We then investigated the reaction route via the analysis of the products. 1,3-Propanediol, hydroxypropanone, ethylene glycol, oxalic acid, glycolic acid, formaldehyde, formic acid, and 1,2-propanediol, were detected in the reaction of glycerol (Supplementary Fig. 7). The observed products were separately employed as reactants (Fig. 2d). No methanol was generated from 1,3-propanediol and hydroxypropanone. Although glyceraldehyde and glycerol acid were not detected, they are possibly formed via the oxidation of the primary hydroxyl group. A minor amount of methanol was formed with glyceraldehyde and glycerol acid as an initial substrate, indicating that they are not intermediate on rout to methanol. EG is a possible intermediate on rout to methanol as it was detected in the reaction and could be converted to methanol with a high yield. Glycolic acid and oxalic acid were majorly converted to $\mathrm{CO}_{2}$. Formaldehyde and formic acid were decomposed to a mixture of $\mathrm{CO}, \mathrm{CO}_{2}$ and $\mathrm{H}_{2}$ under the reaction conditions.

Based on the above results, a possible reaction route for the photo-reforming of glycerol to methanol was proposed (Fig. 5a). Upon photoirridiation, the adsorbed glycerol undergoes $\mathrm{C}-\mathrm{C}$ bond cleavage, forming hydroxymethyl radical and EG radical which were in situ captured by the addition of styrene (Supplementary Fig. 8). The coupling of EG and hydroxymethyl radicals with hydrogen atoms leads to the formation of EG and methanol, respectively. EG further undergoes $\mathrm{C}-\mathrm{C}$ bond cleavage to hydroxymethyl radicals. The further oxidation of intermediates by $\mathrm{HO}$ - radicals results in the formation of overoxidation products, such as glycolic acid and oxalic acid. The decarboxylation glycolic acid produces methanol and $\mathrm{CO}_{2}$. Oxalic acid is finally decomposed to $\mathrm{CO}_{2}$ and $\mathrm{H}_{2}$. Oxidation of hydroxymethyl carbon radicals results in the formation of formaldehyde and formic acid, which could be further decomposed to $\mathrm{CO}, \mathrm{CO}_{2}$, and $\mathrm{H}_{2}$.

The $\mathrm{Cu} / \mathrm{TNR}$ shows higher activity than other $\mathrm{TiO}_{2}$ supported copper catalysts in the $\mathrm{C}-\mathrm{C}$ bond cleavage of polyols to methanol. 

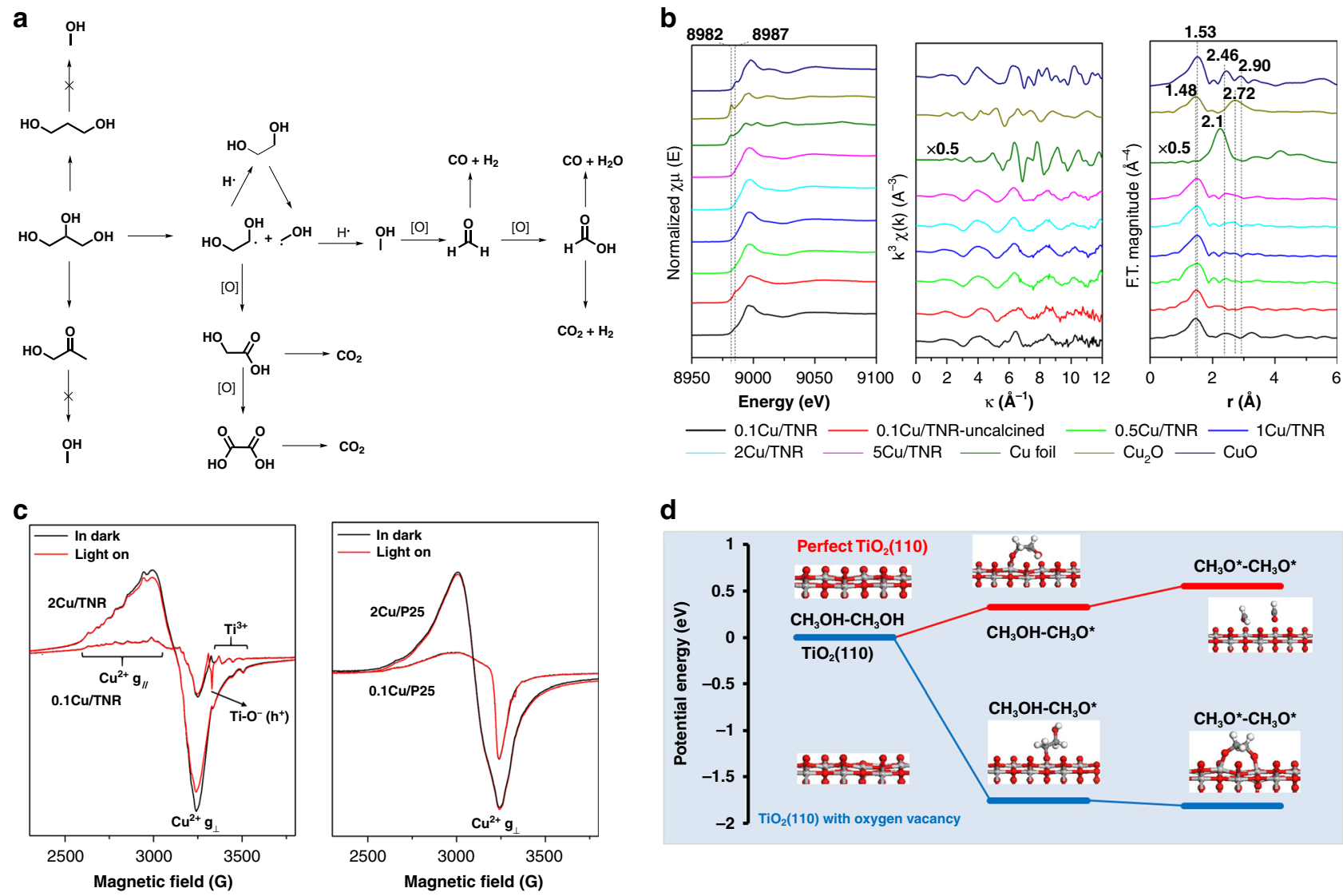

d
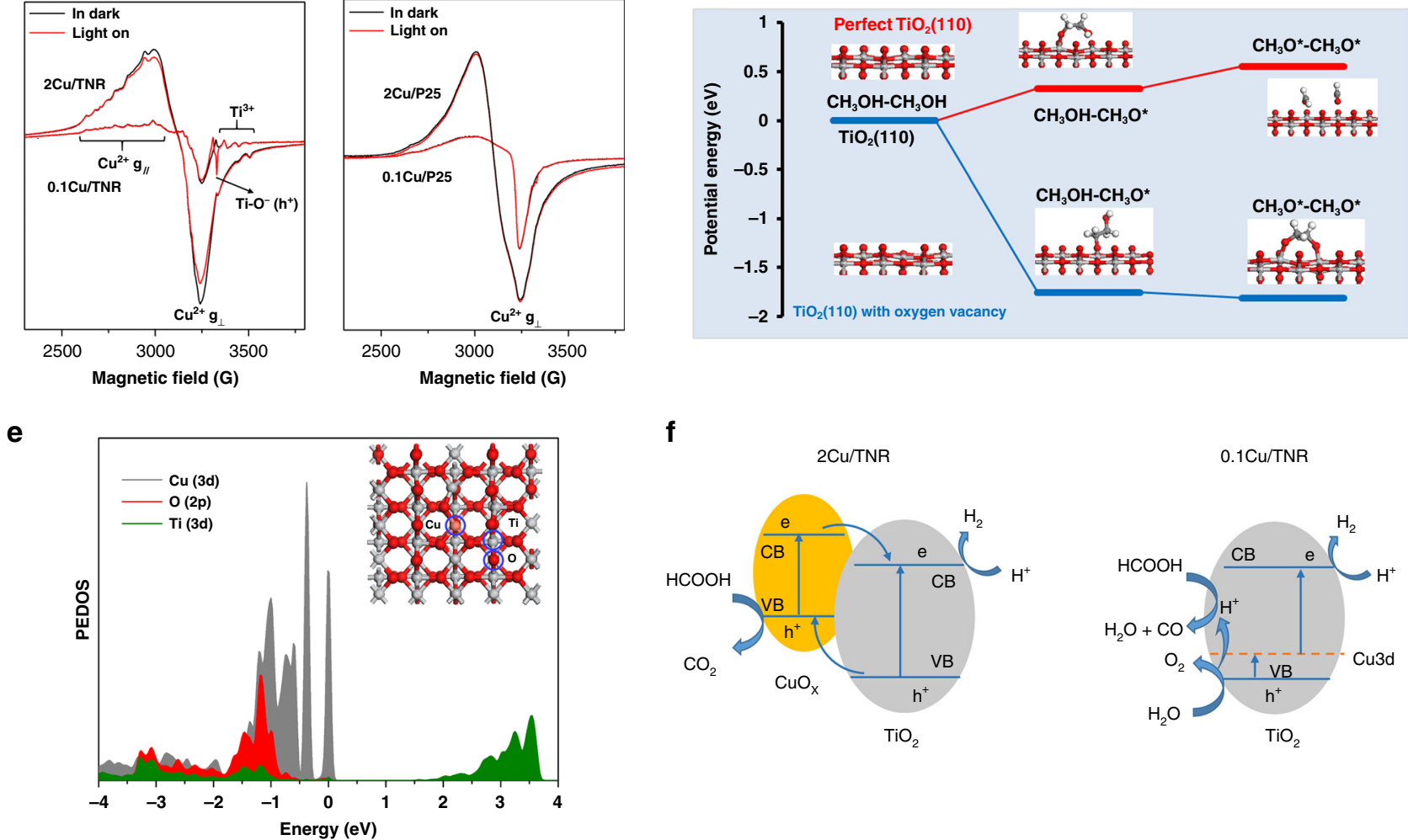

f
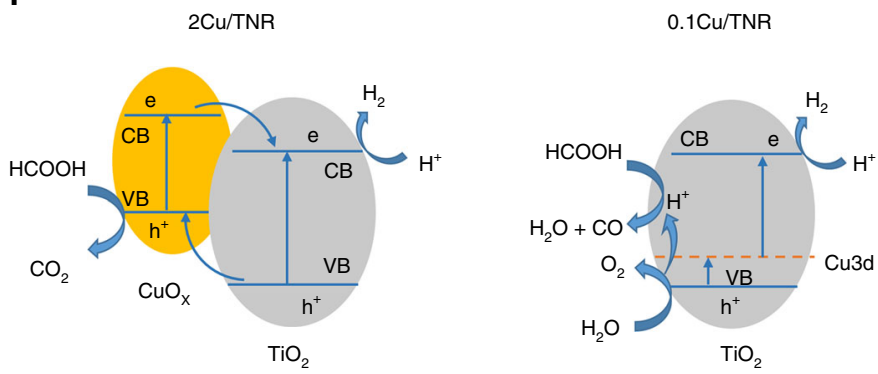

Fig. 5 Catalyst characterization and reaction mechanism study. a Reaction route for the conversion of glycerol to methanol and syngas. $\mathbf{b} X A F s$ characterization of copper samples. $\mathbf{c}$ EPR spectra. d DFT calculation of the EG adsorption on the $\mathrm{TiO}_{2}(110)$ surface. e PEDOS of copper doped TiO 2 . $\mathbf{f}$ The proposed model for the photodecomposition of formic acid over 2Cu/TNR and 0.1Cu/TNR.

We performed electron paramagnetic resonance (EPR) characterization (Fig. $5 \mathrm{c}$ ) and found that $\mathrm{Cu} / \mathrm{TNR}$ is full of oxygen vacancies as evidenced by the appearance of $\mathrm{Ti}^{3+}$ species ${ }^{29,30}$, while $\mathrm{Ti}^{3+}$ species is not obvious for $\mathrm{Cu} / \mathrm{P} 25$. The oxygen vacancy plays a key role in the adsorption and activation of polyols according to DFT calculations (Fig. 5d). The adsorption and activation of EG on the $\mathrm{TiO}_{2}(110)$ surface with or without oxygen vacancy were considered. Compared with perfect $\mathrm{TiO}_{2}(110)$ surface, $\mathrm{TiO}_{2}$ with the oxygen vacancy is more thermodynamically favored for activation of substrate via dissociative adsorption. EG dissociative adsorption on $\mathrm{TiO}_{2}(110)$ surface is exothermic $(-1.75 \mathrm{eV})$ while endothermic on the perfect $\mathrm{TiO}_{2}(110)$ surface $(0.33 \mathrm{eV})$.
The gas product distribution is dominantly controlled by the decomposition way of formic acid. There are two pathways for the decomposition of formic acid. The dehydrogenation of formic acid produces $\mathrm{CO}_{2}$ and the dehydration of formic acid generates $\mathrm{CO}$ (Fig. 5a). We further investigated copper loading effect of $\mathrm{Cu} / \mathrm{TNR}$ catalysts in the decomposition of formic acid. The similar trend that with glycerol as substrate was observed and the $\mathrm{CO} / \mathrm{CO}_{2}$ ratio decreased with the increase of the copper loading (Supplementary Fig. 9), indicating that $\mathrm{Cu} / \mathrm{TNR}$ with low copper loading favors the dehydration of formic acid and $\mathrm{Cu} / \mathrm{TNR}$ with high copper loading favors the dehydrogenation of formic acid.

The $\mathrm{CO}$ could also be produced from photoreduction of $\mathrm{CO}_{2}$ over $\mathrm{Cu} / \mathrm{TNR}$. We further used ${ }^{13} \mathrm{C}$ labeling experiments to study 
the source of $\mathrm{CO}$. The photoreforming of glycerol was carried out in the presence of ${ }^{13} \mathrm{CO}_{2}$. After reaction, the gas phase was analyzed by mass spectroscopy. Only a small peak of ${ }^{13} \mathrm{CO}$ was appeared (Supplementary Fig. 10). The results demonstrated that the $\mathrm{CO}$ can be both derived from the decomposition of the intermediates (such as formic acid) in the liquid phase and the reduction of $\mathrm{CO}_{2}$ in the gas phase, and the former is the dominant way for the generation of CO from glycerol.

We further performed characterizations to understand the origin of the significant loading effect of copper on the photo decomposition of formic acid to form $\mathrm{CO}$ or $\mathrm{CO}_{2}$. No copper oxide phase was detected by X-ray diffraction (XRD) for $\mathrm{Cu} / \mathrm{TNR}$ samples (Supplementary Fig. 11). X-ray of photoelectron spectroscopy (XPS) only detected $\mathrm{Cu}^{+}$species with its $\mathrm{Cu} 2 p_{3 / 2}$ binding energy at approximately $932.4 \mathrm{eV}$ (Supplementary Fig. 12), which is supposed to be formed via reduction of $\mathrm{Cu}^{2+}$ by $\mathrm{Ti}^{3+}$ during the calcination process ${ }^{31} \cdot \mathrm{Cu}^{2+}$ species in $\mathrm{Cu} / \mathrm{TNR}$ samples were detected by EPR (Fig. $5 \mathrm{c}$ ). The $\mathrm{Cu}$ K-edge X-ray absorption near edge structure (XANES) spectra of and the corresponding differential spectra (Fig. 5b, Supplementary Discussion) confirm the presence of both $\mathrm{Cu}^{2+}$ dopants and $\mathrm{CuO}_{\mathrm{x}}$ particles. In the preedge of XANES spectra, $0.1 \mathrm{Cu} / \mathrm{TNR}$ displays a characteristic $\mathrm{Cu}^{2+}$ peak at $8987 \mathrm{eV}$. In $\mathrm{r}$ space, all the samples show a strong $\mathrm{Cu}-\mathrm{O}$ peak but very weak $\mathrm{Cu}-\mathrm{Cu}$ peaks, indicating the $\mathrm{Cu}^{2+}$ is highly dispersed in the $\mathrm{TiO}_{2}$. As the copper loading amount increases, weak $\mathrm{Cu}-\mathrm{Cu}$ peaks at $2.57 \AA(\mathrm{CuO})$ and $2.60 \AA\left(\mathrm{Cu}_{2} \mathrm{O}\right)$ gradually become more obvious, indicating the $\mathrm{CuO}_{\mathrm{x}}$ clusters or nanoparticles are formed. Copper oxide nanoparticles are observed by transmission electron microscope (TEM) with copper loading above 2 wt\% (Supplementary Fig. 13). These results suggest that $\mathrm{CuO}_{\mathrm{x}}$ particles and $\mathrm{Cu}^{2+}$ dopants coexist in the $\mathrm{Cu} / \mathrm{TNR}$, forming $\mathrm{CuO}_{\mathrm{x}}-\mathrm{TiO}_{2}$ heterojunction and $\mathrm{Cu}^{2+}$ defect level (Fig. 5e). With increasing the copper loading amount, the dominant copper species are gradually transformed from the single copper dopants to $\mathrm{CuO}_{\mathrm{x}}$ particles. Therefore, $\mathrm{CuO}_{\mathrm{x}}-\mathrm{TiO}_{2}$ heterojunction dominates in high copper loading and $\mathrm{Cu}^{2+}$ defect level prevails in low copper loading (Supplementary Fig. 14).

It is reported that the dehydrogenation of formic acid is more thermodynamically favorable than the dehydration reaction. Under thermal conditions $\left(100{ }^{\circ} \mathrm{C}\right), \mathrm{TiO}_{2}, \mathrm{CuO}$, and $\mathrm{Cu}_{2} \mathrm{O}$ are all inactive in the decomposition of formic acid. Under light irradiation, the dehydrogenation reaction takes place over $\mathrm{CuO}$ and $\mathrm{Cu}_{2} \mathrm{O}$ and generates $100 \%$ selectivity of $\mathrm{CO}_{2}$, while the dehydration reaction is preferable over $\mathrm{TiO}_{2}$, affording $68 \%$ selectivity of $\mathrm{CO}$ and $32 \%$ selectivity of $\mathrm{CO}_{2}$ (Supplementary Fig. 15). The results are in accordance with the thermal decomposition of the formic acid demonstrated by the calculations and surface science experiments: copper phase prefers to follow dehydrogenation reaction to afford $\mathrm{CO}_{2}$, while $\mathrm{TiO}_{2}$ phase favors the dehydration reaction to generate $\mathrm{CO}^{32-34}$. We conducted the FTIR characterization of formic acid adsorption on $\mathrm{Cu} / \mathrm{TNR}$ samples (Supplementary Fig. 16). With low copper loading, the spectra of formic acid adsorption on $0.1 \mathrm{Cu} / \mathrm{TNR}$ is similar to the formic acid adsorption on $\mathrm{TiO}_{2}{ }^{35}$. The bands at 1360 and $1581 \mathrm{~cm}^{-1}$ are assigned to -COO- symmetric and antisymmetric stretches, $1378 \mathrm{~cm}^{-1}$ is signed to $\mathrm{C}-\mathrm{H}$ deformation. With increasing the copper loading, the bands changed. Besides the shifting of the -COO- symmetric and antisymmetric stretches, new bands at 1650 and $1609 \mathrm{~cm}^{-1}$ appeared which are probably due to the formic acid adsorption on $\mathrm{CuO}_{\mathrm{x}}$. These results clearly explain the copper loading amount effect on the $\mathrm{CO} / \mathrm{CO}_{2}$ ratio (Fig. $5 \mathrm{f}$ ). For the $\mathrm{Cu} / \mathrm{TNR}$ with high copper loading amount $(2 \mathrm{Cu} / \mathrm{TNR}), \mathrm{CuO}_{\mathrm{x}}$ nanoparticles are dominant and a $\mathrm{CuO}_{\mathrm{x}}-\mathrm{TiO}_{2}$ heterojunction is formed. Upon photoexcitation, the photoexcited holes in the valance band $(\mathrm{VB})$ of $\mathrm{TiO}_{2}$ transfer to $\mathrm{VB}$ of $\mathrm{CuO}_{\mathrm{x}}$. Therefore, the oxidation of formic acid by holes takes place on the $\mathrm{CuO}_{\mathrm{x}}$ phase, and formic acid is decomposed to $\mathrm{CO}_{2}$ and $\mathrm{H}_{2}$ via dehydrogenation reaction. For the $\mathrm{Cu} / \mathrm{TNR}$ with low copper loading amount $(0.1 \mathrm{Cu} / \mathrm{TNR}), \mathrm{Cu}^{2+}$ single site is doped into the lattice of $\mathrm{TiO}_{2}$, forming a defect level in the bandgap. The photoexcited holes remain in the $\mathrm{TiO}_{2}$, which is further confirmed by EPR characterization. Upon photoirradiation, the typical holes $\left(\mathrm{Ti}-\mathrm{O}^{-}\right.$) signal appears in $0.1 \mathrm{Cu} / \mathrm{TNR}^{36}$, but not in $2 \mathrm{Cu} / \mathrm{TNR}$ (Fig. 5c). It is reported that the oxidation of water by holes on $\mathrm{TiO}_{2}$ generates acid, which is permanent under photoirradiation and distributed close to the surface ${ }^{37}$. Because there is no $\mathrm{CuO}_{\mathrm{x}}$ phase in $0.1 \mathrm{Cu} / \mathrm{TNR}$, the formic acid dominantly adsorbed on $\mathrm{TiO}_{2}$ phase. For $0.1 \mathrm{Cu} / \mathrm{TNR}$, the holes on $\mathrm{TiO}_{2}$ oxidize water to in situ generate acidic $\mathrm{TiO}_{2}$ surface under photoirradiation, which may promote the dehydration of formic acid to $\mathrm{CO}$ and $\mathrm{H}_{2} \mathrm{O}$.

\section{Discussion}

We provided a mild way for the conversion of polyols and sugars into methanol and syngas via photo splitting. Cu dispersed on titanium oxide nanorod (Cu/TNR) is effective for the conversion of biomass into syngas and methanol under UV light irradiation at room temperature. The TNR is rich in oxygen vacancy and favors for the activation of polyols via dissociative adsorption. The water concentration and copper loading are two factors that influence the $\mathrm{CO} / \mathrm{CO}_{2}$ ratio. Water favors for the overoxidation of organic species to carboxylic acids which decompose to $\mathrm{CO}_{2}$ via decarboxylation. Decreasing water content suppresses the formation of $\mathrm{CO}_{2}$. The copper loading amount controls the decomposition way of the formic acid intermediate. For the $\mathrm{Cu} /$ TNR with high copper loading amount, a $\mathrm{CuO}_{\mathrm{x}}-\mathrm{TiO}_{2}$ heterojunction is formed and the oxidation of formic acid by holes on the $\mathrm{CuO}_{\mathrm{x}}$ phase generates to $\mathrm{CO}_{2}$ and $\mathrm{H}_{2}$. For the $\mathrm{Cu} / \mathrm{TNR}$ with low copper loading amount, $\mathrm{Cu}^{2+}$ dopants are dominant. Formic acid undergoes dehydration on $\mathrm{TiO}_{2}$ surface to form $\mathrm{CO}$. A series of biomass resources, including polyols and sugars, could be converted into syngas and methanol. Because the methanol and syngas are feedstocks of the current petrochemical and chemical industries, the present biomass to methanol/syngas process is promising for the utilization of biomass to produce useful commodities for modern society.

\section{Methods}

Preparation of $\mathbf{C u} /$ TNR. First, protonated titanate nanotubes (H-TNTs) were prepared using the alkaline hydrothermal synthesis. Briefly, $3.0 \mathrm{~g}$ of $\mathrm{TiO}_{2}$ powder (anatase $\mathrm{TiO}_{2}$, Macklin reagent, purchased from Beijing Puyihua Science and

Technology CO., LTD) were dispersed into $90 \mathrm{~mL}$ of $10 \mathrm{M} \mathrm{NaOH}$ aqueous solution under stirring. After stirring for $24 \mathrm{~h}$, the alkaline suspension was transferred into an autoclave with Teflon inner and statically heated at $150^{\circ} \mathrm{C}$ for $48 \mathrm{~h}$. The H-TNTs were recovered by washing with $0.1 \mathrm{M}$ dilute $\mathrm{HNO}_{3}$ solution and deionized water till neutral. Then, $\mathrm{NH}_{4}$ exchanged $\mathrm{TiO}_{2}$ nanotubes $\left(\mathrm{NH}_{4}\right.$-TNTs) were prepared from $\mathrm{H}$-TNTs using $\mathrm{NH}_{4} \mathrm{Cl}$ as the $\mathrm{N}$-sources. Briefly, $18 \mathrm{~g}$ of $\mathrm{NH}_{4} \mathrm{Cl}$ was added in a $100 \mathrm{~mL}$ ethanol-water solution (1:1 volume ratio). The as-recovered H-TNTs were then well dispersed in the $\mathrm{NH}_{4} \mathrm{Cl}$ solution prior to heating reflux at $120^{\circ} \mathrm{C}$ for $12 \mathrm{~h}$ After cooling to room temperature, the resulting white precipitates were filtrated and washed with deionized water and ethanol. The obtained $\mathrm{NH}_{4}$-TNTs were dried at $80^{\circ} \mathrm{C}$ overnight prior to calcination at $400{ }^{\circ} \mathrm{C}$ for $2 \mathrm{~h}$. Finally, $\mathrm{Cu}^{2+}$-exchanged hydrogen titanate was prepared by an ion-exchange reaction of $\mathrm{NH}_{4}$-TNTs in $\mathrm{Cu}$ $\left(\mathrm{NO}_{3}\right)_{2}$ aqueous solution. Typically, $0.5 \mathrm{~g}$ of $\mathrm{NH}_{4}$-TNTs was dispersed in $20 \mathrm{~mL}$ of deionized water, into which a certain volume of $\mathrm{Cu}\left(\mathrm{NO}_{3}\right)_{2}$ aqueous solutions $\left(0.1 \mathrm{~mol} \cdot \mathrm{L}^{-1}\right)$ was added. The mixture was stirred for $24 \mathrm{~h}$ at room temperature and then heated at $100{ }^{\circ} \mathrm{C}$ overnight to remove water. The acquired powders were put in a quartz tube and calcined at $450^{\circ} \mathrm{C}$ for $2 \mathrm{~h}$ in pipe furnace with a heating rate of $2{ }^{\circ} \mathrm{C} \mathrm{m^{-1 }}$ and $25 \mathrm{~mL} \mathrm{~min}^{-1}$ flow of air. The samples with calculated $\mathrm{Cu}$ weight percentages of $0.05,0.2,0.5,1,2$, and $5 \%$ were prepared and denoted as $\mathrm{XCu} / \mathrm{TNR}$, where $\mathrm{X} \%$ denotes the $\mathrm{Cu}$ weight percentages.

Reaction procedure and product analysis. The reaction was carried out in homemade LED photoreactors. Typically, $10 \mathrm{mg}$ of substrate and $10 \mathrm{mg}$ of catalyst were added into $1 \mathrm{~mL}$ of solvent in a $6.5 \mathrm{~mL}$ of quartz tube reactor, then the system was completely replaced with Ar before sealed with a cap. This quartz tube reactor 
could stand up $0.5 \mathrm{MPa}$ pressure. The quartz tube was then irradiated with $365 \mathrm{~nm}$ LED light $\left(18 \mathrm{~W}, 55 \mathrm{~mW} \mathrm{~cm}^{-2}\right)$ via side irradiation. The reaction temperature was kept between 25 and $35^{\circ} \mathrm{C}$. After the reaction, gas-phase products were analyzed by mass spectroscopy (MS) and gas chromatography (GC) equipped with a TCD detector and TDX-01 column. The gas was injected into the mass spectroscopy and GC via an injector. The liquid phased was analyzed by the GC equipped with FID detector and GDX-02 column, and high performance liquid chromatography (HPLC) equipped with a hydrogen column (Hi-Piex H, $300 \times 7.7 \mathrm{~mm})$. Propanol was added into the reaction liquid as the internal standard. The catalyst was filtered, and the supernatant was used for the GC and HPLC analysis.

\section{Data availability}

All data generated and analyzed during this study are included in this Article and its Supplementary Information or are available from the corresponding author upon reasonable request.

Received: 6 October 2019; Accepted: 10 February 2020;

Published online: 27 February 2020

\section{References}

1. Shih, C. F., Zhang, T., Li, J. \& Bai, C. Powering the future with liquid sunshine. Joule 2, 1925-1949 (2018).

2. Tian, P., Wei, Y. X., Ye, M. \& Liu, Z. M. Methanol to olefins (MTO): from fundamentals to commercialization. ACS Catal. 5, 1922-1938 (2015).

3. Rostrup-Nielsen, J. R. Syngas in perspective. Catal. Today 71, 243-247 (2002).

4. Huber, G. W., Iborra, S. \& Corma, A. Synthesis of transportation fuels from biomass: chemistry, catalysts, and engineering. Chem. Rev. 106, 4044-4098 (2006).

5. Ragauskas, A. J. et al. Lignin valorization: improving lignin processing in the biorefinery. Science 344, 1246843 (2014).

6. Wang, M. et al. Sustainable productions of organic acids and their derivatives from biomass via selective oxidative cleavage of C-C bond. ACS Catal. 8 , 2129-2165 (2018).

7. Puga, A. V. Photocatalytic production of hydrogen from biomass-derived feedstocks. Coord. Chem. Rev. 315, 1-66 (2016).

8. Kuehnel, M. F. \& Reisner, E. Solar hydrogen generation from lignocellulose. Angew. Chem. Int. Ed. 57, 3290-3296 (2018).

9. Kasap, H., Achilleos, D. S., Huang, A. \& Reisner, E. Photoreforming of lignocellulose into $\mathrm{H} 2$ using nanoengineered carbon nitride under benign conditions. J. Am. Chem. Soc. 140, 11604-11607 (2018).

10. Wakerley, D. W. et al. Solar-driven reforming of lignocellulose to $\mathrm{H}_{2}$ with a CdS/CdOx photocatalyst. Nat. Energy 2, 17021 (2017).

11. Zhu, L. F. et al. Study on the methanol catalytic synthesis from biomass syngas. Adv. Mater. Res. 347-353, 2524-2527 (2012).

12. Yin, X. L. et al. Characteristics of the synthesis of methanol using biomassderived syngas. Energ. Fuel. 19, 305-310 (2005).

13. Cheng, K. et al. Bifunctional catalysts for one-step conversion of syngas into aromatics with excellent selectivity and stability. Chem 3, 334-347 (2017)

14. Jiao, F. et al. Selective conversion of syngas to light olefins. Science 351 1065-1068 (2016).

15. Devi, L., Ptasinski, K. J. \& Janssen, F. J. J. G. A review of the primary measures for tar elimination in biomass gasification processes. Biomass. Bioenerg. 24, 125-140 (2003).

16. Soares, R. R., Simonetti, D. A. \& Dumesic, J. A. Glycerol as a source for fuels and chemicals by low-temperature catalytic processing. Angew. Chem. Int. Ed. 45, 3982-3985 (2006).

17. Shabaker, J. W., Huber, G. W., Davda, R. R., Cortright, R. D. \& Dumesic, J. A. Aqueous-phase reforming of ethylene glycol over supported platinum catalysts. Catal. Lett. 88, 1-8 (2003).

18. Sarma, B. B. \& Neumann, R. Polyoxometalate-mediated electron transferoxygen transfer oxidation of cellulose and hemicellulose to synthesis gas. Nat. Commun. 5, 4621 (2014).

19. Gullu, D. \& Demirbas, A. Biomass to methanol via pyrolysis process. Energy Convers. Manage. 42, 1349-1356 (2001).

20. $\mathrm{Wu}, \mathrm{C}$. T. et al. A non-syn-gas catalytic route to methanol production. Nat. Commun. 3, 2053 (2012).

21. Haider, M. H. et al. Efficient green methanol synthesis from glycerol. Nat. Chem. 7, 1028-1032 (2015).

22. Pagliaro, M., Ciriminna, R., Kimura, H., Rossi, M. \& Della Pina, C. From glycerol to value-added products. Angew. Chem. Int. Ed. 46, 4434-4440 (2007).

23. Zou, J., Zhang, G. \& Xu, X. X. One-pot photoreforming of cellulosic biomass waste to hydrogen by merging photocatalysis with acid hydrolysis. Appl Catal. A 563, 73-79 (2018)
24. Zhang, G. et al. Simultaneous cellulose conversion and hydrogen production assisted by cellulose decomposition under UV-light photocatalysis. Chem. Commun. 52, 1673-1676 (2016).

25. Yin, X. L., Leung, D. Y. C., Chang, J., Wang, J. F. \& Wu, C. Z. Study on biomass gasification methanol synthesis system. Energ. Environ. 1, 261-267 (2003).

26. Ye, T. Q. et al. Bio-methanol from bio-oil reforming syngas using dual-reactor. Chinese. J. Chem. Phys. 24, 457-463 (2011).

27. Ribeiro, A. M., Santos, J. C. \& Rodrigues, A. E. PSA design for stoichiometric adjustment of bio-syngas for methanol production and co-capture of carbon dioxide. Chem. Eng. J. 163, 355-363 (2010).

28. Lee, S. G. \& Sardesai, A. Liquid phase methanol and dimethyl ether synthesis from syngas. Top. Catal. 32, 197-207 (2005).

29. Chiesa, M., Paganini, M. C., Livraghi, S. \& Giamello, E. Charge trapping in $\mathrm{TiO} 2$ polymorphs as seen by electron paramagnetic resonance spectroscopy. Phys. Chem. Chem. Phys. 15, 9435-9447 (2013).

30. Caretti, I., Keulemans, M., Verbruggen, S. W., Lenaerts, S. \& Van Doorslaer, S Light-induced processes in plasmonic Gold/TiO 2 photocatalysts studied by electron paramagnetic resonance. Top. Catal. 58, 776-782 (2015).

31. Liu, Y. X. et al. $\mathrm{TiO}_{2} / \mathrm{Cu}_{2} \mathrm{O}$ core/ultrathin shell nanorods as efficient and stable photocatalysts for water reduction. Angew. Chem. Int. Ed. 54, 15260-15265 (2015).

32. Aizawa, M., Morikawa, Y., Namai, Y., Morikawa, H. \& Iwasawa, Y. Oxygen vacancy promoting catalytic dehydration of formic acid on $\mathrm{TiO}_{2}(110)$ by in situ scanning tunneling microscopic observation. J. Phys. Chem. B 109, 18831-18838 (2005).

33. Morikawa, Y. et al. First-principles theoretical study and scanning tunneling microscopic observation of dehydration process of formic acid on a $\mathrm{TiO}_{2}(110)$ surface. J. Phys. Chem. B 108, 14446-14451 (2004).

34. Onishi, H., Aruga, T. \& Iwasawa, Y. Catalytic reactions on a metal-oxide single-crystal-switchover of the reaction paths in formic-acid decomposition on $\mathrm{TiO}_{2}(110)$. J. Am. Chem. Soc. 115, 10460-10461 (1993).

35. Liao, L. F., Wu, W. C., Chen, C. Y. \& Lin, J. L. Photooxidation of formic acid vs formate and ethanol vs ethoxy on $\mathrm{TiO}_{2}$ and effect of adsorbed water on the rates of formate and formic acid photooxidation. J. Phys. Chem. B 105, 7678-7685 (2001)

36. Berger, T. et al. Light-induced charge separation in anatase $\mathrm{TiO}_{2}$ particles. $J$. Phys. Chem. B 109, 6061-6068 (2005).

37. Ulasevich, S. A. et al. Light-induced water splitting causes high-amplitude oscillation of $\mathrm{pH}$-sensitive layer-by-layer assemblies on $\mathrm{TiO}_{2}$. Angew. Chem. Int. Ed. 55, 13001-13004 (2016)

\section{Acknowledgements}

We would like to show our thankfulness to Dr. Yi-Tao Cui (LASOR/ISSP, The University of Tokyo, Japan), Dr. Lei Li (SRNC, University of Hyogo, Japan), Drs. Hirofumi Ishii, Yen-Fa Liao (NSRRC, the Republic of China) for their contributions to the XAFS measurement and data analysis. We thank M. Y. Zheng in Dalian Institute of Chemical Physics, Chinese Academy of Society for providing the hydrogenated cellulose solution. This work was supported by the National Natural Science Foundation of China (21872135), the Strategic Priority Research Program of Chinese Academy of Sciences (XDB17020300) and the Fundamental Research Funds for the Central Universities (DUT19LK39).

\section{Author contributions}

M.W. conducted most of the experiments of the project and data analysis and wrote the manuscript. M.J.L. performed the catalyst characterization. J.M.L. performed the DFT calculations. F.W. supervised the research and revised the manuscript.

\section{Competing interests}

The authors declare no competing interests.

\section{Additional information}

Supplementary information is available for this paper at https://doi.org/10.1038/s41467 020-14915-8.

Correspondence and requests for materials should be addressed to F.W.

Peer review information Nature Communications thanks Moritz Kuehnel and the other, anonymous, reviewer(s) for their contribution to the peer review of this work. Peer reviewer reports are available.

Reprints and permission information is available at http://www.nature.com/reprints

Publisher's note Springer Nature remains neutral with regard to jurisdictional claims in published maps and institutional affiliations. 
(c) Open Access This article is licensed under a Creative Commons Attribution 4.0 International License, which permits use, sharing, adaptation, distribution and reproduction in any medium or format, as long as you give appropriate credit to the original author(s) and the source, provide a link to the Creative Commons licence, and indicate if changes were made. The images or other third party material in this article are included in the article's Creative Commons licence, unless indicated otherwise in a credit line to the material. If material is not included in the article's Creative Commons licence and your intended use is not permitted by statutory regulation or exceeds the permitted use, you will need to obtain permission directly from the copyright holder. To view a copy of this licence, visit http://creativecommons.org/ licenses/by/4.0/.

(C) The Author(s) 2020 